\title{
Análise dos entraves para implementação da logística reversa em indústrias de Brejo Santo (CE)
}

Com o objetivo de identificar e analisar os entraves percebidos pelos gestores das indústrias da cidade de Brejo Santo (CE) para implementação da logística reversa como elemento favorecedor não apenas do gerenciamento ambiental, mas também com foco na sustentabilidade do negócio, o estudo em questão caracterizouse por ser de natureza básica, abordagem qualitativa e uso de fontes bibliográficas realizando o aprofundamento das teorias existentes com enfoque descritivo a partir da aplicação de entrevistas com os gestores das 03 indústrias abordadas, caracterizando-se como um estudo multi casos. 0 estudo leva à compreensão de que os gestores reconhecem a necessidade estratégica de trabalhar a logística reversa de forma integrada com a sua cadeia de suprimento, à medida que essa integração possa baratear as práticas reversas em favor da existência dos bens de produção e participação com meio ambiente. Assim torna-se viável fazer logística reversa estando alinhado com os seus fornecedores, clientes e canais de distribuição, porém ainda visualizam um custo superior à adesão das práticas.

Palavras-chave: Gestão; Logística Reversa; Entraves.

\section{Analysis of the obstacles to the implementation of reverse logistics in industries of Brejo Santo (CE)}

With the objective of identifying and analyzing the obstacles perceived by the managers of the industries of the city of Brejo Santo (CE) to implement reverse logistics as a conducive element not only of environmental management but also with a focus on business sustainability, it is based on a basic nature, a qualitative approach and the use of bibliographical sources. The authors present a deepening of the existing theories with a descriptive approach based on the application of interviews with the managers of the three industries studied, being characterized as a multi case study. The study leads to the understanding that managers recognize the strategic need to work with reverse logistics in an integrated way with their supply chain, as this integration may reduce reverse practices in favor of the existence of production assets and participation with means environment. This makes it possible to do reverse logistics in alignment with its suppliers, customers and distribution channels, but still see a cost higher than adherence to the practices.

Keywords: Management; Reverse Logistic; Inside.

Topic: Gestão Ambiental e da Biodiversidade

Reviewed anonymously in the process of blind peer.
Received: 12/09/2018

Approved: 21/12/2018
Francisca Jayne Gomes da Silva

Centro Universitário Dr. Leão Sampaio, Brasil

http://lattes.cnpq.br/0352851579893841

jaynesilva2011@hotmail.com

\section{Alyne Leite de Oliveira}

Centro Universitário Dr. Leão Sampaio, Brasil

http://lattes.cnpq.br/2112616885682866

alyneoliveira@leaosampaio.edu.br
Referencing this:

SILVA, F. J. G.; OLIVEIRA, A. L.. Análise dos entraves para

implementação da logística reversa em indústrias de Brejo Santo (CE). Revista Brasileira de Administração Científica, v.9, n.3, p.74-90, 2018. DOI: http://doi.org/10.6008/CBPC2179-684X.2018.003.0006 


\section{INTRODUÇÃO}

Com a globalização e o avanço tecnológico tem se percebido o grande desenvolvimento das indústrias e comércios, o município de Brejo Santo (CE) localizado no interior do estado está acompanhando e se desenvolvendo no mercado. Partindo do pressuposto de que a logística é uma área de grande importância para as organizações, Ballou (1993) diz que auxilia da primeira etapa que é a aquisição, até a final, que no caso é a entrega de produto/serviço, ela faz a gestão dos fluxos da informação e o gerenciamento dos sistemas produtivos, visando atender a demanda.

Independentemente do tamanho do negócio, todo empreendimento utiliza toda ou parte da cadeia de suprimentos, sendo necessário o gerenciamento do uso de transporte, controle de estoque e armazenamento. Segundo Dias et al. (2014) nesse mesmo contexto a logística reversa vem se enquadrando com o seu processo voltado não somente para seus fornecedores e clientes, mas agora também com sua participação sócio ambiental. Se preocupando com os malefícios que sua ineficiência poderá causar ao meio ambiente, tomando medidas cabíveis para reverter tais danos ao planeta terra.

Neste processo todos os produtores de qualquer classificação, deveriam prever como seria a devolução, a reciclagem daquele produto e a destinação final adequada, especialmente dos que podem retornar o ciclo produtivo. A preocupação com o meio onde está inserida é parte vital no bom desenvolvimento organizacional, melhorando inclusive a imagem da organização. Tendo em vista os aspectos mencionados, surge o questionamento sobre quais as barreiras percebidas pelos gestores das indústrias da cidade de Brejo Santo (CE) para aplicar a logística reversa no âmbito gerencial e ambiental, assim como também na sustentabilidade do mercado?

A questão adentra a situações hipotéticas que entrelaçam discussões que são: a falta de interesse em ajudar a melhorar o desenvolvimento sustentável da cidade, tornando consequente a falta de informação em logística reversa; o conhecimento de logística reversa se limitando aos custos e não ganhos; o desinteresse quanto ao destino final dos resíduos ou até mesmo acreditar que devem ser preocupações apenas do poder público.

O propósito social deste estudo leva aos gestores Brejo Santo (CE) o assunto da logística reversa e assim planta uma semente de conhecimento quanto à preocupação com os resíduos gerados pela produção das indústrias na cidade, entendendo que existem oportunidades de ganhos, pensando no socioambiental, e assim trazer melhorais para a sua atuação na cidade. Servindo de modelo acadêmico para mais gestores em formação, contribuindo para a sociedade em geral. Levando o conhecimento na área administrativa, visto o favorecimento do campo de estudo e obtenção de resultados.

Desse modo, este estudo pautou-se no objetivo identificar e analisar quais os entraves percebidos pelos gestores das indústrias da cidade de Brejo Santo para implementação da logística reversa como elemento favorecedor não apenas do gerenciamento ambiental, mas também com foco na sustentabilidade do negócio. Para isso tornou-se necessário discutir sobre gestão ambiental, elencar fatores que favorecem o gerenciamento dos resíduos sólidos inerentes às práticas industriais e apresentar aspectos da logística reversa que impulsionam o gerenciamento dos resíduos sólidos e a sustentabilidade como um todo. 


\section{REVISÃO TEÓRICA}

\section{Logística: Surgimento, Conceitos e Atividades}

Diante de um mundo globalizado onde prevalece o acesso a informações em tempo real e o crescente desenvolvimento de tecnologias; mudança de hábitos e compreensão das exigências de qualidade são fatores substanciais às indústrias que desejam melhorar suas operações, mantendo-se competitivas, visando crescimento e expansão de mercado e plenitude de participação (SANTOS, 2017).

Sucena (2012) apresenta maneiras de se tornar eficaz e satisfazer as demandas a partir do redesenho dos processos logísticos de forma mais acurada, controlando os estoques e mantendo-se no menor possível, reduzindo então os seus custos. Ele destaca ainda que é necessário armazenar de forma eficiente para não haver depreciação ou onerosidade, transportar os produtos corretamente e utilizar serviços à medida que aconteça um planejamento de toda a operação.

Para Vieira et al. (2012), e Segreti et al. (2004) toda a origem da logística se iniciou nas guerras com os militares e o gerenciamento usado para manter-se abastecidos nas guerras. Só após a segunda guerra passou a ser parte vital na visão das organizações para o funcionamento de toda a cadeia produtiva, onde satisfaz os clientes, aproxima os fornecedores e melhora os recursos. O produto e o serviço certo, no momento correto, de maneira desejada.

Segundo Alves et al. (2013), a logística tem grande importância nas organizações para se produzir bens e serviços e obter resultados, sendo impossível não a observar nas atividades e operações. Segundo Santos (2017) a logística é parte da cadeia de suprimentos (SCM - Supply Chain Management) que comporta início, meio e fim, ao qual se adquire a matéria prima, produz produtos semiacabados e acabados, distribui aos fornecedores e então se chega às lojas para consumo dos clientes. O foco não é somente no consumidor final, mas sim em todos que participam das atividades com foco Lead times satisfatórias e no Lean manufacturing. A cadeia deve ser integrada em todas as fases, desde a chegada até a saída do produto, de forma intermediaria ou não.

A logística deixou de ser ferramenta para se tornar uma estratégia de bons resultados estando ligado ao SCM que foca na integração do todo levando em consideração o tempo, os custos, os limites, as vantagens e o fluxo de materiais agregados à informação se tornando consequência de uma preparação com a competitividade (SEGRETI et al. 2004).

Com o foco nas atividades de entradas e saídas dos produtos e serviços, que resulta de uma operação de planejamento e estratégias conduzida por sistemas interligados de comandos ativos realizando previsões e gerenciando imprevistos, Santos (2017) destaca a necessidade do gerenciamento dos inputs, para aquisição de quantidade e qualidade dos outputs, sendo a melhoria continua dos processos e demanda, onde todos precisam trabalhar de forma alinhada para as operações não sofram impactos negativos com o fluxo de informação errada.

Visto que as indústrias são abastecidas por entradas de recursos, e que a fabricação depende das matérias primas e das estações de trabalho, se faz necessário o cuidado com o desperdício ou o mau uso desses recursos, o que tem levado as empresas a se preocuparem com suas atividades considerado o quanto 
isso pode afetar o meio ambiente, considerando os retornos e ciclos produtivos em contraste a eficácia da preocupação com discursos dos processos de fabricação para a gestão ambiental (GOMES, 2013).

\section{Gestão Ambiental}

Por muito tempo as pessoas não deram importância para o meio ambiente, visto depois que ele precisa de cuidado e atenção, pois os recursos são finitos e com isso a existência da humanidade, então dependendo de condições de subsistência à própria saúde (NASCIMENTO, 2012).

Dias (2017) relata que os primeiros sinais de preocupação com ambiente surgiram em 1972, onde começou a ficar em evidência que o planeta carece de zelo, e já não pode ser explorado como antes. A população cresce, e as indústrias também e com isso o uso desenfreado do patrimônio da natureza, contudo é quando começa a limitar-se, assim o meio ambiente dá respostas de que precisa de observações.

É possível perceber um enfraquecimento a respeito das soluções e medidas de causas ambientais, sendo que há anos vem se questionando como as pessoas não se preocupam com a biodiversidade, muitas vezes ainda esquecida. Enquanto isso vai se esgotando as riquezas do planeta e tudo o que dele faz parte, sofrendo a fauna e a flora tanto quanto sofrem os que se beneficiam desse desgaste (NEIMAN et al., 2014).

Desta forma deve-se prevenir e controlar os impactos que as organizações podem causar ao meio ambiente, e assim identificar as prioridades para conduzir melhor as ações socioambientais, aperfeiçoando responsabilidades em sentido global, com pensamentos e ferramentas que auxiliem nas políticas ambientais e organizacionais (PEÇANHA, 2012).

É devido também o compromisso vindo da parte estratégica organizacional, fixando assim uma política ambiental simples e objetiva, para que os procedimentos da empresa sejam definidos em favor ao meio e o social, reduzindo os impactos e impulsionando as atividades para melhoria produtiva e ambiental. (CONCEIÇÃO et al., 2011).

Tendo em vista que a sustentabilidade é permanência do equilíbrio das partes do ecossistema em sensatez biológica para qualidade não havendo riscos a existência humana (MIKHAILOVA, 2004). Segundo Conceição et al. (2011) as organizações visando não só a sustentabilidade econômica, mas principalmente o entendimento de que hoje é necessário cuidar e preservar, estando atentos as informações e processos trabalhando no foco da qualidade ambiental, a sociedade por sua vez também opta por empresas com ética e compromisso socioambiental, garantindo os dois outros pilares: ambiental e social. Nesse contexto, se enquadra então a logística reversa junto de uma gestão de estratégias, aproveitando ao máximo dos recursos finitos (DOMENICO et al., 2015).

\section{Logística Reversa}

A logística reversa começou a ter espaço nas discussões em meados dos anos 70 com as definições de canais reversos que começaram a ser abordados por alguns autores da literatura cientifica, mas expressivamente no Brasil a sua aparição começou a acontecer em 1990 quando foi iniciada a visualização de atividade reversa dentro dos processos logísticos, de modo que as matérias primas, os artefatos e as 
previsões possuíam custos importantes e que para melhorá-los teriam que subordinar esses recursos a uma estratégia reversa adequada (SOARES et al., 2017).

As questões socioambientais trazem cada vez mais os importantes e imprescindíveis alamedas da logística reversa, tornando necessária a atuação das empresas de primeiro e segundo setor atuando ativamente no controle de resíduos e de todos os seus originados resquícios (PEREIRA et al., 2017). Sendo a logística reversa a parte da cadeia de suprimentos que delineia, age a direciona o curso dos bens de pósvenda, consumo duráveis ou não, ciclos produtivos a um caminho de valores: econômicos, judicial, logísticos e figura organizacional (LEITE, 2002).

Comumente refletem em logística como o gerenciamento do andamento de materiais ao alvo de aquisição até o seu ponto de abatimento. Porém, permanece também o andamento logístico reverso, do consumo até a ascendência, que precisa ser medido, avaliado e controlado. Para isso existem processos e atividades alcançadas para arrecadar, abstrair, acondicionar e despachar itens usados, afetados ou antiquados do consumo até as zonas de reprocessamento, comercialização ou rejeite (LACERDA, 2002).

Nisso tudo se enquadra a Lei de Política Nacional de Resíduos (Lei 12.305/2010), que põe em seu art. 60 uma classificação dos princípios (BRASIL, 2018). A lei regulamenta os tratamentos de formas corretas de acondicionar, tratar e descartar qualquer resíduo perante a sua funcionalidade.

A interpretação de Machado (2012) a respeito dos princípios: Princípio da prevenção; Princípio da precaução; Princípio poluidor-pagador; Princípio da responsabilidade compartilhada; Princípio da cooperação; Princípio do protetor-recebedor; Princípio da visão sistêmica; Princípio do desenvolvimento sustentável; Princípio da ecoeficiência; Princípio do reconhecimento do valor do resíduo sólido reutilizável e reciclável; Princípio do respeito às diversidades locais e regionais; Princípio da razoabilidade e da proporcionalidade; Princípio do direito da sociedade à informação; Princípio do direito da sociedade ao controle social.

Para isso a logística possui um tratamento direto com clientes e fornecedores, são eles que aparecem de diversas formas no canal produtivo da cadeia, como beneficiados e parceiros. As grandes divisões da logística reversa são de pós-venda, pós-consumo e embalagens (PEREIRA et al., 2011). Segundo Leite (2002) esses campos são entendidos da seguinte forma:

Logística Reversa de pós-venda: Está relaciona com a volta dos insumos depois da venda, sejam eles usados ou não, os motivos desse retorno podem ocorrer pela falta do que esperavam, defeitos dos produtos, danos ou qualquer sentido que leve a rejeição da compra.

Logística Reversa de pós-consumo: Após se utilizar os produtos, esses voltam no sentido que sua vida de consumo já terminou, retornando para se tornar outro material de aproveitamento.

Logística Reversa de embalagem: São produtos que usam a política de venda e retorno obrigatório, que no caso são as astúcias retornáveis.

A logística reversa tem fonte na gestão e acima de tudo na responsabilidade social e ambiental sendo um grande pilar de sustentação das normas dos tratamentos dos resíduos e as formas com que tudo isso se entrelaça com o mecanismo de se ter compromisso com a sociedade onde está atuando. A logística reversa e todos os resultados que fazem parte e precisa-se de cuidados e atenção (RICK et al., 2015). 


\section{Logística Reversa e Responsabilidade Social e com o Meio Ambiente}

A Organização das Nações Unidas (ONU) solicitou em 1968, por mediação da Assembleia Geral, a iniciação da Conferência das Nações Unidas sobre o Meio Ambiente Humano, e assim bloqueou as decorrências das obras antrópica no meio ambiente, que já se apresentava, o planeta começou a emergir suas necessidades e o quanto já havia sofrendo com o uso desregrado dos seus recursos (PEREIRA et al. 2011).

Apesar de alguns países possuírem algumas políticas de retorno de embalagens, não era o suficiente para reduzir os impactos (ADLMAIER et al., 2007). A cadeia de distribuição reversa de pós-consumo duradoura, ainda não é totalmente aplicada a materiais recicláveis no planeta, a disponibilidade acaba sendo mal direcionada por falhas da gestão, tornando-se influência negativa de custo (FORMIGONI et al., 2014).

O elevado indicador de rejeito dos restos palpáveis apontou a suscetibilidade ecológica de determinados consumidores, visto que a população incidiu a ver as dificuldades ocasionadas pela sucessão derradeira imprópria dos resíduos, podendo ocasionar catástrofes ecológicas, adentrando a logística reversa, com o parecer de valorizar insumos e matérias-primas, acrescentando valor a sua vida útil. (RICARDO et al., 2016).

Celere et al. (2007) traz abordagens as questões ambientais, e aprofundas discursões a respeito do tratamento de toda a produção de resíduos no mundo, o aterro sanitário corretamente exercido minimiza os impactos do lixo no planeta. As maiores inquietações ambientais relacionam os bens sólidos acendidos pela sociedade contemporânea e consumidora, que por fim descartam na natureza diversos itens compostos por material orgânico, papel, vidro, plástico e metais. E ainda completa que a dispersão em lixões, aterros controlados e aterros sanitários não devem ser considerados como o ponto final, pois eles possuem capacidade de se reestruturarem.

A logística reversa, gestão ambiental e a responsabilidade social se encontram e com isso gera melhorias para o planeta que é o único lugar no universo até os dias de hoje em que se pode viver. Essa integração se dá a partir da percepção de que a Responsabilidade social é necessária para a conjunção das ações no modelo justo de transformação e benefícios (BERTONCELLO et al., 2007). E para essa existência permanecer é preciso que existam pessoas preocupadas com o bem não somente individual, mas sim coletivo de forma a proporcionar o melhoramento de todos os recursos naturais, utilizando não somente da consciência, mas acima de tudo da ação correta para preservação e prevenção (PÓVOAS, 2015).

\section{METODOLOGIA}

A pesquisa é de natureza básica, objetivo descritivo, abordagem qualitativa, utilizando-se inicialmente de fontes bibliográficas para fundamentar o estudo, seguido de estudos multi casos (YIN, 2001). A natureza do presente estudo prática e acende as noções novas, favoráveis ao progresso da ciência, abrange veracidade e preocupes universais (MERRIAN, 1998).

O enfoque em empregar os métodos qualitativos buscando esclarecer o porquê da existência de acontecimentos e fatos, explanando o que deve ser realizado, não baseando em valores assim como também 
nos retornos simbólicos nem se debelam a verdade dos fatos, sendo os dados levantados e de interação, assim de diferentes abordagens, o foco descritivo estabelece informações sobre todo o entrelaço da pesquisa com relação aos seus objetivos, descrevendo os episódios e acontecimentos da realidade (SILVEIRA et al., 2009).

O estudo ocorreu a partir de entrevistas com os gestores das indústrias localizadas na cidade, especificamente 3 (três) gestores, sendo então das indústrias situadas na cidade e das maiores produtoras. As empresas foram escolhidas intencionalmente, e os participantes da pesquisa teriam que ter pelo menos um ano de atuação na empresa, e estar atuando nos setores de produção, administrativo ou direção dela, e terem disponibilidade para participar do estudo. Como exclusão, classificam estarem gozando férias no período do estudo, ou em algum tipo de licença (maternidade ou doença).

Para coleta de dados foi utilizado um roteiro de entrevista estruturado de autoria do pesquisador e gravação das mesmas por meio de um aparelho gravador (SONY, Icd-Px 240 4gb) e uma observação assistemática dos processos realizados pelas empresas. A estrutura do formulário para os gestores se dividiu em categorias, sendo elas: quatro $\left(1^{\circ}, 2^{\circ} 3^{\circ}\right.$ e $\left.4^{\circ}\right)$ perguntas voltadas para o conhecimento sobre a estratégia da logística e abordagem de algumas das práticas como visão, três $\left(5^{\circ}, 6^{\circ}\right.$ e $\left.7^{\circ}\right)$ sobre o foco da pesquisa e seu entendimento sobre logística reversa, quatro $\left(8^{\circ}, 9^{\circ}\right.$ e 10 e $\left.11^{\circ}\right)$ que contemplaram a suas ramificações quanto à atividade exercida referentes ao aspecto de gestão ambiental e resíduo sólido e quatro $\left(12^{\circ}, 13^{\circ}\right.$, $14^{\circ}$ e $15^{\circ}$ ) que finalizaram a discussão em logística reversa e responsabilidade social.

A análise dos dados ocorreu por meio da análise de conteúdo, assim tratadas por meio do software Iramutec. O julgamento textual expõe o material colhido pelo pesquisador fazendo uma análise do conteúdo apresentado com base nas estatísticas das palavras para os fins relacionados e confrontados a escrita com as diferentes variáveis, específicas para descrever o que foi produzido em texto (CAMARGO et al., 2013). A pesquisa atendeu os objetivos propostos e segue as normas de conduta segundo as Resoluções Éticas Brasileiras, em especial a Resolução CNS 466/12 e 510/16.

\section{RESULTADOS E DISCUSSÃO}

No arranjo da análise, foi realizado inicialmente o esclarecimento do tema proposto com face ao objetivo central da pesquisa situando os gestores sobre a decorrência do estudo em aplicação do formulário semiestruturado com perguntas discursivas. Como forma de complementar a abordagem foi dada um tempo para os gestores lerem o roteiro e repassarem as mesmas antes mesmo de serem perguntados na coleta gravada.

A sopese dos dados das questões foi convertido ao entendimento do software de analise textual Iramutec com a transição das gravações na integra para compor o julgamento de classes, grupos e modelos de palavras que mais se destacaram nas discussões com os gestores nomeados por: Gestor 1, Gestor 2 e Gestor 3. A sequência dos números obedece às datas das entrevistas.

Apresentou-se nos relados dos gestores a logística como real importância para o sucesso da indústria. Onde houve a aparição nos argumentos de que se utiliza diariamente da logística a cada operação, 
confirmando a afirmação de Sucena (2012) que faz junção dos processos básicos da logística, que são controle de estoque, processamento de pedido e armazenamento e assim caracterizando as demais funções estratégicas para obtenção de resultados e maiores competitividade no mercado.

Quadro 2: Logística.

\begin{tabular}{|l|l|l|l|}
\hline Gestor 1 & Gestor 2 & Gestor $\mathbf{3}$ & Tema central \\
\hline "Todos os dias são feitos pedidos & "Tempo de entrega, de transporte & "A logística do processamento de & A logística tida \\
de encomenda, se negocia com & e da mesma forma é a saída, ou & pedido, controle de estoque e & como função \\
fornecedores, são traçados rotas & seja, o produto pronto, eu & armazenamento para acomodar a & base \\
para \\
de entregas, é produzido de & também tenho que obedecer a & produção ao mesmo tempo em & atender \\
domingo a domingo, são & esse sistema de logística, então & que planejo as saídas são coisas & atividades \\
abastecidos os canais de venda e a & geralmente quando vem o pedido & básicas que fazem parte do exercidas dentro \\
matéria prima todo dia chega à & ele já vem com uma data de & controle diário da indústria". & da indústria. \\
fábrica de manhã cedo". & entrega especificada". & & \\
\hline
\end{tabular}

Onde ainda destacam a logística sendo a grande causadora das estratégias para formar o sucesso organizacional, dependendo de cada parâmetro calculado seja ele produtivo ou de decisão, completando assim o relato de Alves et al. (2013). Em conversa com o segundo gestor foram abordadas questões moldadas para a cadeia de suprimentos como um todo em abordagens com ferramentas da qualidade para junção com a logística e obtenção de maiores resultados desempenhado. Em fala é expresso a seguinte posição: "modelo Lean manufacturing de produção, é onde temos que ter os estoques mínimos, para tentar pelo Lead time do negócio como um todo, muitas vezes a gente se confunde e utiliza em prática apenas o Lead time da fábrica, mas na verdade esse Lead time é altamente influenciado pela cadeia como um todo [...] a logística é inteiramente ligada à estratégia da empresa, por mais que nós não quiséssemos ela mexe inteiramente no resultado operacional da empresa. Forças internas e forças externas confrontando a todo o momento", consolidando assim as questões abordadas por Santos (2017).

$\mathrm{Na}$ análise de Reinert AFC, que melhor exemplifica a aproximação das variáveis de acordo com as formas ativas e suplementares em graus de maiores aparições e posições de emprego as frases para palavras mais repetitivas, dando maior destaque às cores mais intensas do gráfico e sua aproximação.

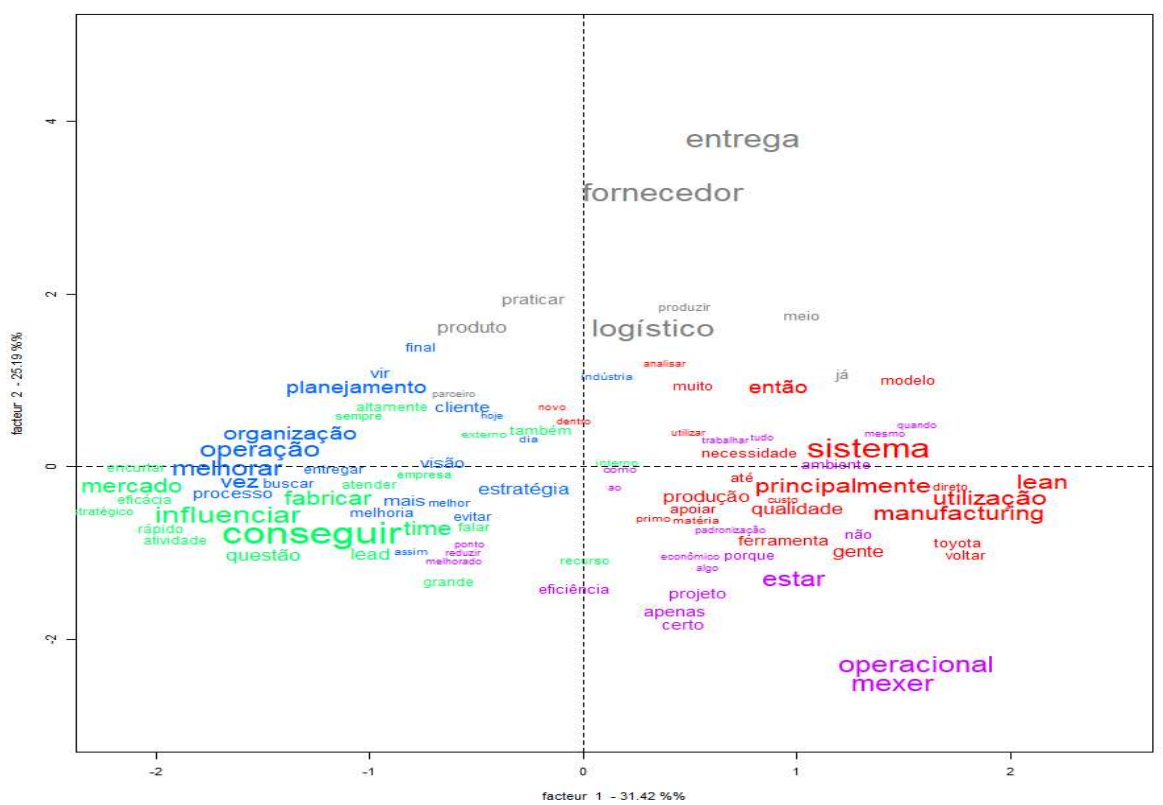

Gráfico 1: Reinert AFC. Fonte: Dados do Software Iramuteq (2018). 
As palavras que mais aparecem no corpus do texto em análise do gráfico 1 foram dividias em cinco classes de variáveis que se cruzam por diferentes extremidades, dando ênfase as palavras mais vistas que são: "sistema", "manufacturing", "operações", "operacional", "conseguir", "melhorar", "utilização" e "organização". Essas classes podem ser visualizadas pelas palavras tanto quanto em barras no Reinert Dendrograma nas porcentagens, que ilustra as representativas para as variáveis em questão tidas pelas cores vistas por cada palavra.

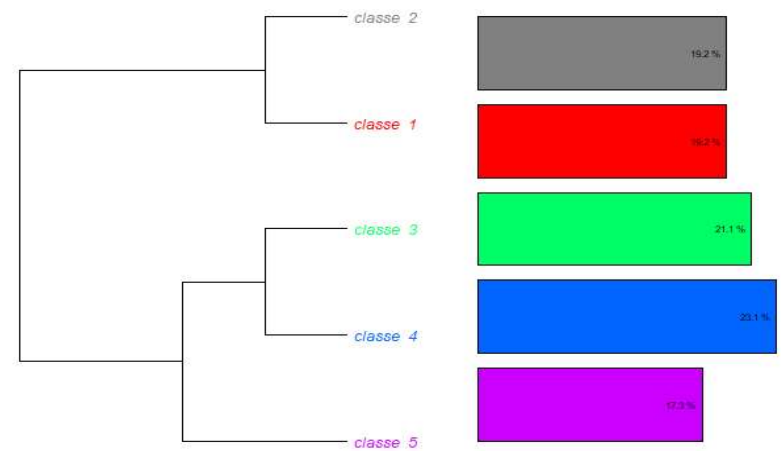

Gráfico 2: Reinert Dendrograma. Fonte: Dados do Software Iramuteq (2018).

No gráfico 2 são distribuídas as classes de palavras pelas cores, no caráter da representação de proximidades entre grau de aparições. Vista na análise Reinert Dendrograma a porcentagem das classes que são: vermelha $(19,2 \%)$ e cinza $(19,2 \%)$ que melhor se cruzam onde podemos encontrar confins repetitivas entre as palavras das cores vistas no gráfico 1 por "fornecedor" e "sistemas". As classes verdes $(21,1 \%)$ e azul $(23,1 \%)$ no quadrante por palavras "conseguir" e "melhorar". Bem como a classe lilás $(17,3 \%)$ e verde pelas expressões "lead time" e "eficiência". Onde finalizam a relevância de importantes palavras tidas no corpus do texto analisado.

Acendendo destaque para a ponte feita por Gomes (2013) em relacionar a logística estratégica com os aspectos da logística reversa surge na observação das entrevistas a relação que se faz de uma tanto quanto a outra, por se completarem pelos custos e necessidades de aplicação. Adentrando o que foi mencionado pelos gestores encontra-se sentido nas conclusões de melhorias contínuas ditas por Soares, Pereira e Cândido (2017) em realizar a transições das operações com o custo benéfico de maiores eficiências com os produtos, a matéria prima e os resíduos para a subordinação reversa. Ao entendimento dos gestores sobre logística reversa foram destacadas nas respostas da visão dos gestores nos conceitos de logística reversa:

Quatro 3: Logística Reversa.

\begin{tabular}{|c|c|c|c|}
\hline Gestor 1 & Gestor 2 & Gestor 3 & Tema central \\
\hline $\begin{array}{l}\text { "A logística reversa é algo que só deve } \\
\text { servir para melhorar as atividades } \\
\text { dentro da empresa, pois possibilita } \\
\text { melhor execução inclusive de } \\
\text { aproveitamento da mateira prima até } \\
\text { retirar o seu valor de custo. Onde } \\
\text { aproveito minha matéria prima em } \\
\text { todos os seus sentidos e aumento a } \\
\text { minha capacidade de produção. Vai } \\
\text { enxugar o custo e fazer com que não } \\
\text { ocorram penalizações acerca de } \\
\text { alguma norma". }\end{array}$ & $\begin{array}{l}\text { "Se olhar para a qualidade } \\
\text { como uma ferramenta irá } \\
\text { enxergar a logística reversa } \\
\text { como uma dificuldade, } \\
\text { pela questão do modelo } \\
\text { como é trabalhado no } \\
\text { nosso país que tem muitos } \\
\text { entraves, mas se eu a olhar } \\
\text { com sentimento eu vou } \\
\text { entender como ganho, } \\
\text { necessidade e solução". }\end{array}$ & $\begin{array}{l}\text { "logística reversa é entendido } \\
\text { como o modelo logístico que } \\
\text { deve ser trabalhado e } \\
\text { melhorado, pois é importante } \\
\text { para o meio ambiente como um } \\
\text { todo, evitando contaminação e } \\
\text { poluição pela sua produção, } \\
\text { tornando a empresa mais } \\
\text { competitiva no mercado e } \\
\text { melhor vista, como } \\
\text { instrumento de marketing e } \\
\text { benefício social". }\end{array}$ & $\begin{array}{l}\text { "A logística reversa } \\
\text { favorece os custos, } \\
\text { mas quando se tem o } \\
\text { entendimento que ela } \\
\text { pode ajudar a empresa } \\
\text { a melhorar suas } \\
\text { atividades, marketing e } \\
\text { participação no } \\
\text { mercado". }\end{array}$ \\
\hline
\end{tabular}


Com os questionamentos voltados para o entendimento dos gestores sobre a logística reversa fechou-se o ciclo da cadeia de distribuição para as estratégias voltadas sobre os custos e necessidades investidas na logística reversa, visto que para alguns dos gestores deixa-se a ideia de que praticar logística reversa depende muito da política dos resíduos aplicados nacionalmente. Em fala do gestor 2: "A logística reversa deve ser algo pensado e trabalhado no Brasil em especial, pela ideia de como ela ainda é aplicada e pela forma como ela foi desenhar tornou muito caro o investimento por parte daquele que produz. As empresas querem fazer, porém entendem como muito caro, então é mais barato não fazer logística reversa. Os selos ambientais geram um marketing muito positivo, porém ainda não é bem trabalhado como deveria.". Afirmações do gestor 1: "algumas coisas passavam despercebidas, como a água que realizava a lavagem do produto, que antes era descartada em um córrego e nisso sabia-se que era errado, mas não tinha orientação do órgão responsável para ajudar a descartar forma correta". Onde relaciona as afirmações de Nascimento (2012), pela necessidade do caminho de valores e controle de resíduos e de todos os seus originados resquícios.

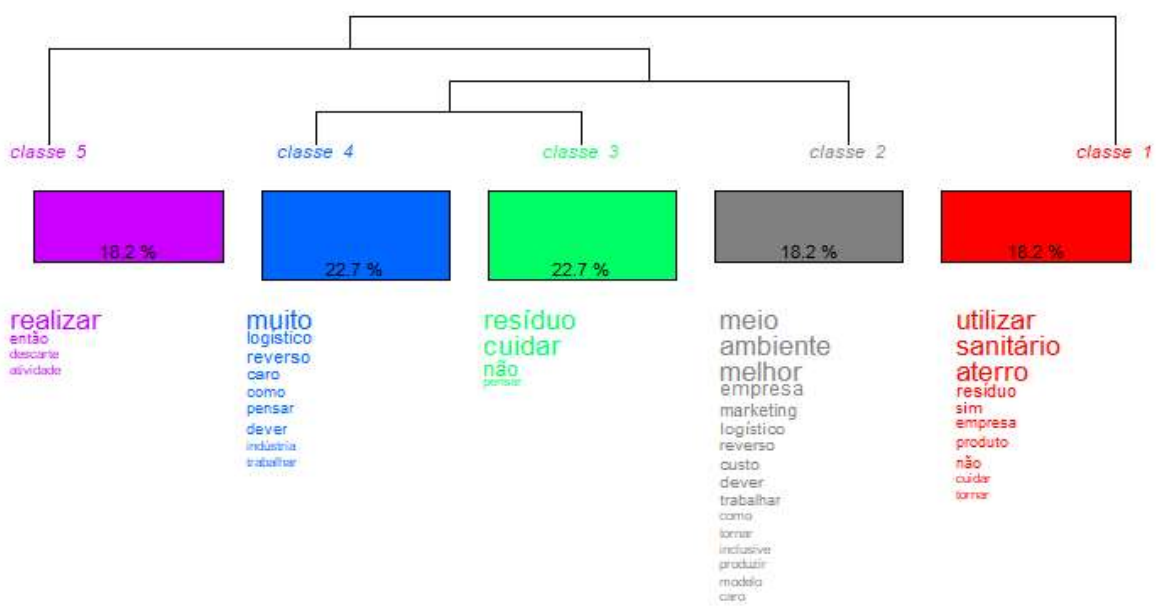

Grafico 3: Dendrogramme CHD1. Fonte: Dados do Software Iramuteq (2018).

Em derivas do corpus texto apresentado pela discussão, os questionamentos levantam palavras chaves que configuram as suas assertivas como respostas. Visto no gráfico 3 como um fluxograma de palavras de análise fatorial de ramificações usa o emprego das palavras provocadas por variações de percentuais. Os subcorpos da classe 1 faz jus a "utilizar" bem como relacionado ao sentido "sanitário" e "aterro". Os compostos da classe 2 "meio" complementam "ambiente" e "melhor". Na classe 3 torna "resíduo" associado ao uso dos termos "cuidar". Se concentram na classe 4 "muito" bem como "logístico" e "reverso". Na classe 5 os parâmetros de "realizar" condizem com "descarte". Como sendo as principais palavras dos grupos classificam por cores pelo nível como elas se repetem nas falas dos gestores havendo a uma concordância para as respostas.

Com os esclarecimentos do gestor 3 tem-se os seguintes relatos: "a visão da empresa acompanhada por uma boa política de participação com o meio ambiente, a imagem é contribuída à medida que a economia é a neutralização por arte dos resíduos produzidos. Atentando-se ao pós-venda e pós consumo", o que confirma a posição de Leite (2002). 


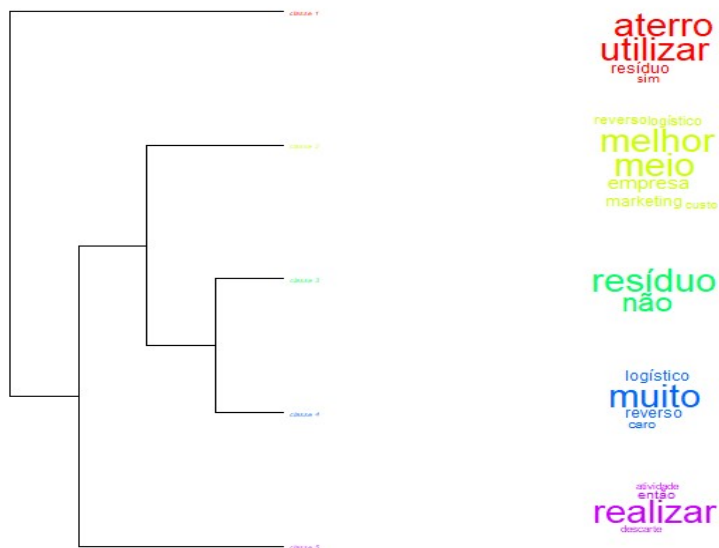

Grafico 4: CHD1. Fonte: Dados do Software Iramuteq (2018).

O gráfico 4 enfatiza as práticas necessárias a logística reversa, como subcorpos das classes apresentadas "utilizar", "melhor", "resíduos", "muito" e "realizar", sendo as palavras que representam as informações passadas pelos gestores como mecanismos que implicam as práticas reversas. Onde foram discutidas pelas acessões em que toma à logística reversas sendo as "operações voltadas para o bem-estar da existência da indústria", discutido por Lacerda (2002) como comercialização ou adequação dos rejeitos.

Adentrado os aspectos da validação da política dos resíduos sólidos obteve-se como respostas o que mais se usa no dia a dia da indústria e a visão do gestor pela melhor execução de tais políticas. Como os modelos de gestão ambiental voltados para a preocupação quanto à geração de resíduos e seus tratamentos.

Quadro 4: Resíduos sólidos.

\begin{tabular}{|c|c|c|c|}
\hline Gestor 1 & Gestor 2 & Gestor 3 & Tema central \\
\hline $\begin{array}{l}\text { "Sim, reaproveitar o } \\
\text { máximo. E esse tem sido o } \\
\text { maior proposito de investir } \\
\text { em mais produtos extraídos } \\
\text { da minha mateira prima, } \\
\text { sendo que é algo que } \\
\text { quando lançar meus novos } \\
\text { produtos irie proporcionar". }\end{array}$ & $\begin{array}{l}\text { "O reaproveitamento por parte } \\
\text { da política de PGRS, que é o } \\
\text { plano de gerenciamento dos } \\
\text { resíduos sólidos, as emissões de } \\
\text { gases também está dentro do } \\
\text { permitidos. Assim como as } \\
\text { caixas de papelão são } \\
\text { retornáveis.". }\end{array}$ & $\begin{array}{l}\text { "Os resíduos são } \\
\text { reaproveitados por nós e } \\
\text { reciclados por outra } \\
\text { empresa que cuida dos } \\
\text { resíduos, e qualquer } \\
\text { resíduo da cor preta é } \\
\text { reaproveitado dentro do } \\
\text { seu processamento de } \\
\text { trabalho". }\end{array}$ & $\begin{array}{l}\text { "A política interna de } \\
\text { reaproveitamento de resíduos } \\
\text { se aplica as necessidades de não } \\
\text { desperdício e assim } \\
\text { caracterizando } \\
\text { preocupação com os custos } \\
\text { investidos ao desperdício de } \\
\text { tempo produtivo e mão de } \\
\text { obra". }\end{array}$ \\
\hline
\end{tabular}

Ao levantamento dos dados observou-se a necessidade no entendimento de práticas voltadas para políticas ambientais válidas para a produção e geração de resíduos. 0 gestor 2 destacou a utilização de modelos dentro dos seus custos possíveis, onde uma outra empresa faz o trabalho de incineração dos resíduos, bem como o gestor 3 que discutiu o fato de pagar para uma empresa cuidar dos seus resíduos para reciclagem, tornando-se fonte para um novo segmento.

Os dois gestores destacaram que se utilizam do aterro sanitário apenas para os resíduos comuns como exemplo: banheiro e higiene pessoal. Celere et al. (2007) destacam que os resíduos gerados não podem ir para o aterro da cidade, cuidando assim do meio onde estão exercendo suas atividades e Machado (2012) enfatiza ainda do princípio do respeito às diversidades locais e regionais. 0 gestor 3 relata que "também que é reaproveitado algumas peças de defeitos ou realizadas vendas por um preço menor para que os custos em matéria prima e mão de obra não se percam na produção deste bem", abrindo espaço para uma nova base produtiva e estímulos com os insumos, gerando a sustentabilidade. 
Para as bases da logística reversa e suas ramificações com gestão ambiental e responsabilidade social são postos os ganhos e melhorias por se utilizar e entender o cruzamento deles para um propósito único. Em esclarecimentos, o gestor 1 apontou "ganho e melhoria juntos, pois possibilita a participação naquilo que antes era rejeitado ou muitas vezes não sabia como reaproveitar, onde é melhorado ao máximo tudo que pode ser feito inclusive com a matéria prima onde está o maior custo benéfico da produção, abrindo destaque para aproveitamento da matéria prima até a extração total dos seus custos agregados, inclusive aumento do mix de produtos", relacionando diretamente às afirmações de Ricardo et al. (2016).

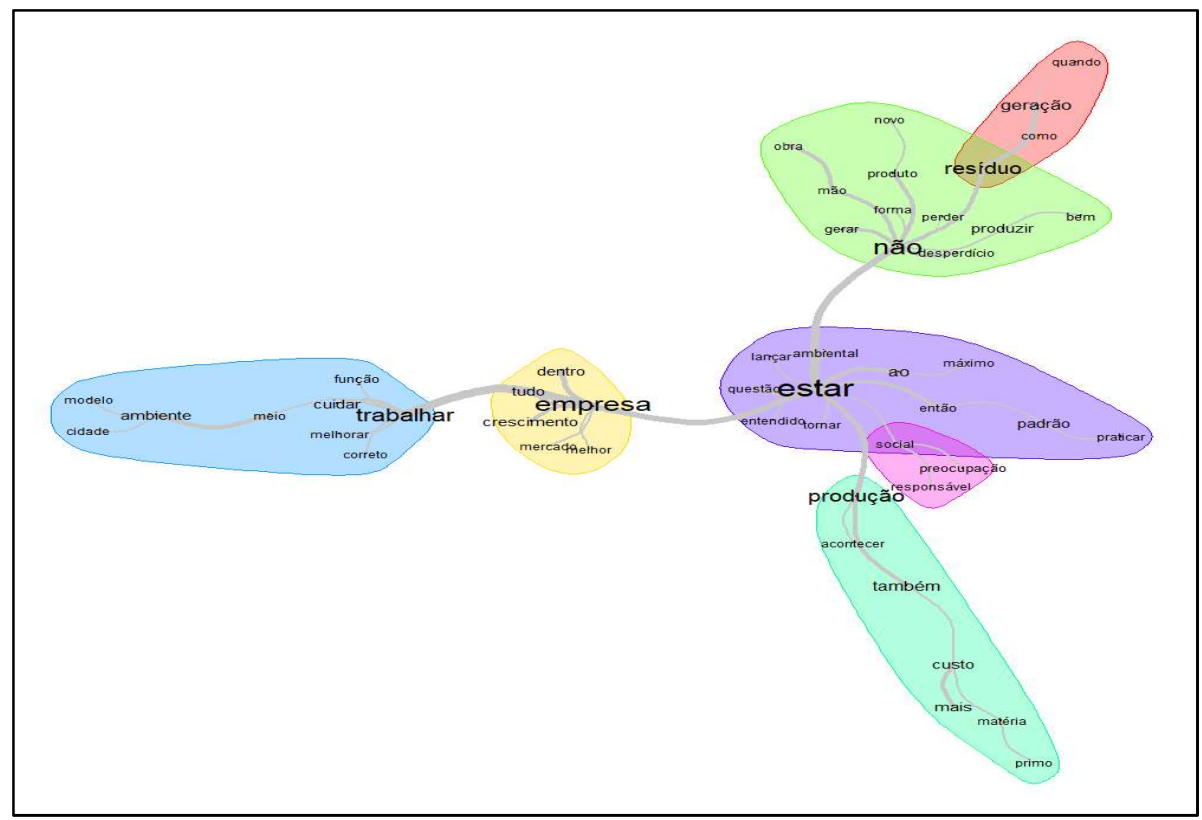

Gráfico 5: Similitude 1. Fonte: Dados do Software Iramuteq (2018).

As palavras de maior destaque no gráfico similitude 1 são: "trabalhar", "estar", "produção", "empresa", "não" é "resíduos", onde preza pela ordem de semelhança das palavras para obedecer a qualidade do texto, formando uma planta com raízes e subcorpos. Nas extremidades acima: "resíduos" embasa "como", "geração" e "quando". Assim como "não" atrela "desperdício", "produzir", "bem", "perder", "formar", "gerar", "mão de obra", "produto novo". Centralizados: "trabalhar" que puxa por "modelo", "cidade", "ambiente”, "meio", “cuidar", "função", "melhorar" e "correto", ao caminho está "empresa” com as expressões "dentro", "tudo", "crescimento", "mercado" e "melhor", na raiz central "estar" com palavras complementares ao seu sentido está, "ambientais", e "padrão". Logo abaixo como base "preocupação" para as palavras "responsável" e "social". A palavra "produção" completam com "acontecer" que é extremidade baixa. O gráfico expressa a homogeneidade apresentada por cada gestor em relação aos modelos internos praticados individualmente pela gestão ambiental.

No tocante à gestão ambiental, o gestor 1 traz destaque na fala: "As maiores práticas ambientais estão nos descartes correto e nos tratamentos da produção para que não haja poluição, dentro das normas" (sic). O gestor 2 cita: “A matéria prima é algo que deve ser estudado em função de serem esgotáveis, os consumos desses resíduos devem ser trabalhados e enxugados para evitar as percas e reduzir ao máximo a geração de agrotóxico, mão de obra, embalagens ao padrão de contribuir com pratica de redução e não desperdício". E o gestor 3 relata: “A gestão ambiental acontece primeiramente em estar correta a produção 
pelas normas ambientais, não trabalhando fora dos padrões e buscado sempre melhorar, sendo que muitas vezes é o entrave para competir no mercado. Trabalhar nas regularizações evita penalidades e perca de mercado" (PÓVOAS, 2015).

Quadro 5: Responsabilidade social.

\begin{tabular}{|c|c|c|c|}
\hline Gestor 1 & Gestor 2 & Gestor 2 & Tema central \\
\hline $\begin{array}{l}\text { "A responsabilidade social } \\
\text { são direcionamento para } \\
\text { sempre fazer o bem e } \\
\text { praticar o correto, a } \\
\text { compreensão e o apoio } \\
\text { daqueles que precisam } \\
\text { como princípios morais para } \\
\text { os direcionamentos éticos". }\end{array}$ & $\begin{array}{l}\text { "A responsabilidade social é } \\
\text { praticada os canais para melhorar } \\
\text { a sociedade em geral, visto que } \\
\text { estamos trabalhando com o que é } \\
\text { permitido para não fugir da } \\
\text { responsabilidade com todos que } \\
\text { participam, e não acabar com os } \\
\text { recursos pela necessidade de } \\
\text { melhoria contínua, pensando na } \\
\text { qualidade ambiental". }\end{array}$ & $\begin{array}{l}\text { "A responsabilidade acontece } \\
\text { principalmente na construção dos } \\
\text { colaboradores que são os } \\
\text { primeiros parceiros da empresa, } \\
\text { onde iram servir de modelo para } \\
\text { os demais que os cercam. A } \\
\text { indústria dentro de uma cidade } \\
\text { não traz apenas geração de } \\
\text { empregos, mas torna-se } \\
\text { responsável por todos que } \\
\text { atuam". }\end{array}$ & $\begin{array}{l}\text { A responsabilidade } \\
\text { social é algo a ser } \\
\text { tomado por todos } \\
\text { principalmente por } \\
\text { aqueles que dela } \\
\text { depende. }\end{array}$ \\
\hline
\end{tabular}

A responsabilidade social apresentada trata dos modelos atrelados ao que comumente enxerga-se nos discursos, visto que dirigir uma indústria traz consigo responsabilidade e dimensões de modelos que se caracterizam por abordagens específicas de cada organização. A semelhança de se preocupar com as pessoas que fazem parte da empresa é semelhança vital dos gestores, com foco nos canais reversos para atuarem diretamente com a preocupação com a sua produção de resíduos e gestão deles. A empresa é socialmente responsável por tudo que produz e com o destino que é aplicado ao mesmo.

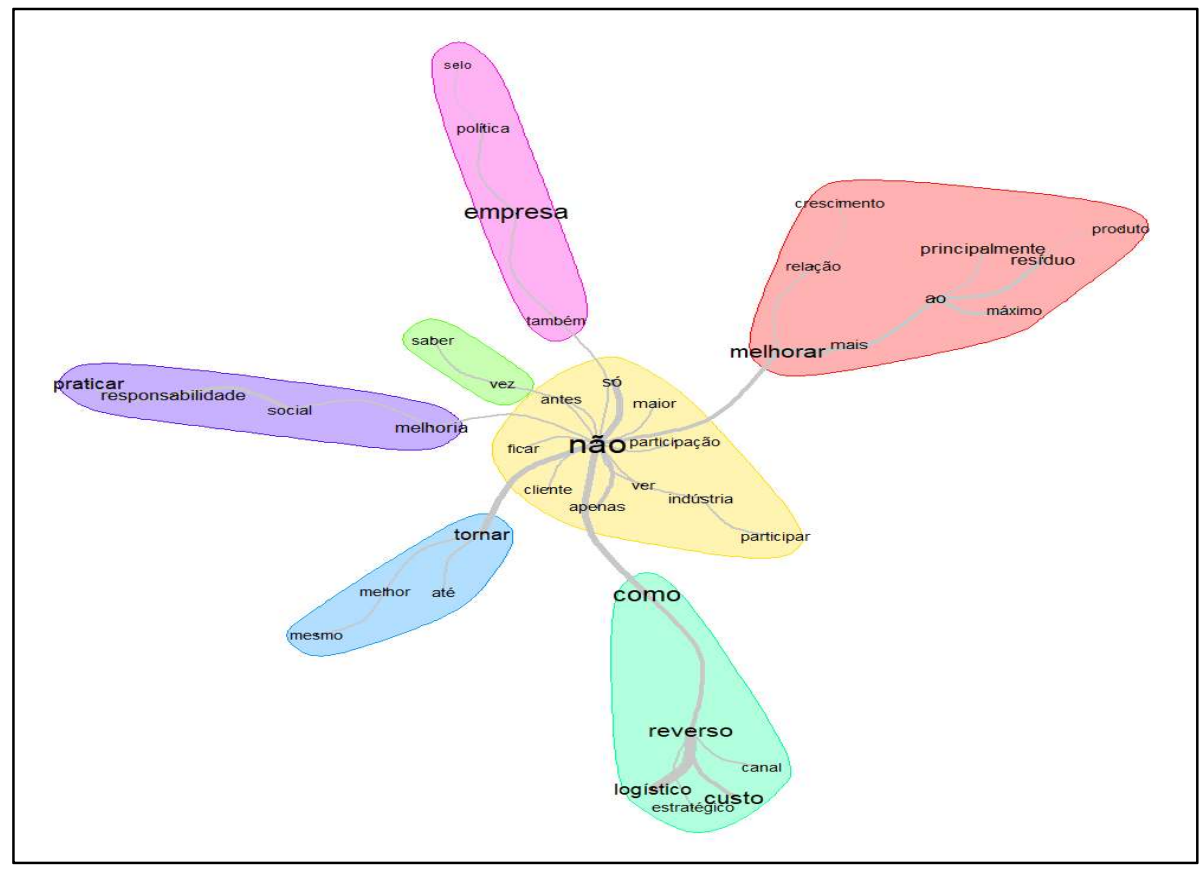

Gráfico 6: Similitude 2. Fonte: Dados do Software Iramuteq (2018).

As palavras se repetem constantemente nos discursos apresentados na análise, com isso abre maior relevância as expressões: "praticar", "tornar", "não", "saber", "empresa”, "reverso" e "melhorar". Pode-se identificar que o gestor 1 pontuou que: "A responsabilidades dos canais reversos não só melhoram como torna visivelmente mais conhecida e a deixa em maiores vantagens com relação aos concorrentes". Que é ressaltado na fala o gestor 2: "Para que as atividades ocorram de forma homogênea deve ser mudada por 
completo a visão de custo e melhoria, sendo que melhoram e fica mais vantajoso quando é praticado por todos os clientes e fornecedores". Completa o gestor 3 com a afirmativa: "torna possíveis os retornos de seus resíduos ao ciclo produtivo, agregando valor econômico de serviços no aspecto geral, maior competitividade e maior satisfação do cliente consumidor. Palavra chave em relação aos canais reversos é conscientização". (RICK et al., 2015)

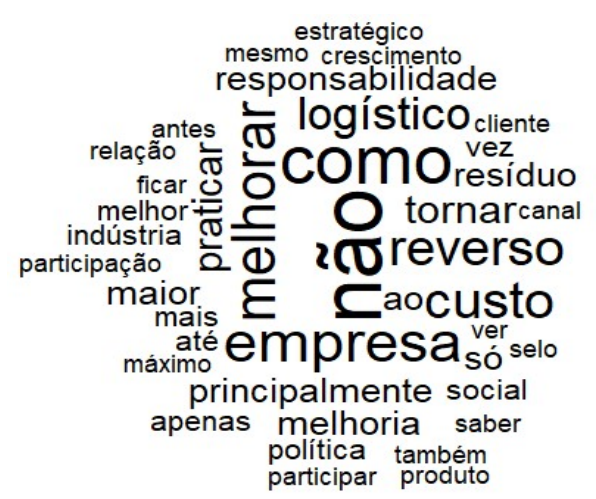

Gráfico 7: Nuage. Fonte: Dados do Software Iramuteq (2018).

No gráfico 7 forma-se nuvens de palavras onde é preenchido com o mesmo grau o conteúdo por relevância aproximada, onde remete o sentido de preservar o conteúdo central e suas diretrizes para compor uma informação. Com saliência para as palavras: "melhorar", "empresa”, "não", "custos", "logísticos", "reversos" e "como". À medida que as informações da análise se complementam com bases nos dados fornecidos produzindo de igual semelhança as causas e efeitos das palavras como base dos discursos dos gestores. O corpus geral foi constituído por 3 textos de 4 módulos que foram separados por rateio de abordagens específicas em vários segmentos de textos (ST), com aproveitamento médio de 78,40\%.

Após encerramento das entrevistas e observações pontuais junto à análise dos dados no software, pode-se chegar à conclusão de que a logística reversa é dita nas indústrias e muitas vezes trabalhado pelos modelos que melhor convém as suas atividades, porém uma ressalva para os custos investidos de forma secundaria onde abre o espaço para se investir cada vez mais. Desta forma fica entendido que os gestores enxergam a logística como elemento favorecedor, mas para se completar a sua é colocado em peso o seu real valor agregado aos canais reversos de forma que a ampliação de resultados muitas vezes depende do custo associado. Desde que parta de uma iniciativa de alavancar os negócios e melhorar sua margem de atuação dentro do mercado. Foi possível observar também as reais preocupações em atender os chamados das normas e políticas ambientais.

\section{CONSIDERAÇÕES FINAIS}

Para complementar as duas analises em observações semiestruturada e do software compreendeuse que há interesse dos gestores em ajudar a melhorar sua atuação dentro da cidade, sendo capaz de absorver as táticas viáveis para o entendimento de informação tanto em logística reversa quanto em gestão ambiental para melhoria de estratégias que favoreçam o contexto organizacional nas funções táticas e operacionais, assim como é bem visto e conhecido à logística reversa acerca dos custos e ganhos. 
Desta forma deixa-se claro que depende muitas vezes de ter capital suficiente para adotar melhores práticas, com o interesse não apenas ao destino dos resíduos, mas sim em acreditar que devem ser preocupações do primeiro setor tanto quanto o segundo e de todos diretamente ou não fazem parte. Os assuntos específicos levantados na observação deixam-se evidente que já faz parte das estratégias as melhorias dos recursos esgotáveis e as necessidades de consumos da matéria prima de forma bruta ou acabada, para isso busca-se medidas para desenvolver a sustentabilidade nas dimensões propostas.

As indagações hipotéticas se esclarecem à medida que aparece na compreensão das falas o interesse e proposito em ajudar a melhorar no desenvolvimento sustentável e a participação social, onde aborda a sentença responsável para medir o valor associado a sua existência física, levantando o entendimento em logística reversa e participação na cadeia produtiva, onde se deixa claro as obrigações acarretadas pela produção. A ciência da logística reversa na integração dos princípios trabalhados é melhorada ao nível da capacidade estável do modelo aplicado dentro da indústria a favor de custos e consciência dos ganhos, partindo da realidade diária tratando em primeiro plano a geração dos resíduos individual e coletivo para tratamento e cuidados necessário de suas origens e reaproveitamento. Desta forma nega as destilações apontadas pelas dúvidas iniciais da pesquisa acerca do entendimento da logística reversa trabalhada pelos gestores.

Onde pelo objetivo deixa-se evidente e explanam os entraves advindos pela capacidade nata do desempenho da logística reversa, que se faz caso dos modelos trabalhados pelo governo para benéficos e isenção das empresas que se adequam às ideias sociais e ambientais. É integro o entendimento como maior entrave os custos para trabalhar a logística reversa como elemento favorecedor, assim como o setor responsável para medidas deixa muitas vezes inacessível a participação. $O$ custo associado ao benéfico organizacional é mais bem trabalhado na teoria das normas, onde a possibilidade arcada com valor monetário subestima a não a fazer, evitando encarecer a participação no mercado.

As práticas realizadas andam de encontro com a produção e localização da indústria, onde iniciasse na captação dos fornecedores e repasse dos resíduos, assim aprimoram as causas e efeitos para converter o melhor aproveitamento dos resíduos e necessidades produtivas, andando de encontro com a realidade da indústria para conseguir competir e fazer sua parte na gestão ambiental. Características dessa gestão concentram-se no reaproveitamento e produção enxuta, para melhoria do ciclo produtivo e obtenção de maiores resultados. A gestão ambiental é tida pelos gestores como foco estratégico para elencar fatores que favorecem o gerenciamento dos resíduos nas práticas industriais assim como também base das atividades exercidas, com os aspectos da logística reversa trabalhada onde favorece e impulsiona o gerenciamento dos resíduos sólidos e sustentabilidade.

Sua preocupação com a cidade se baseia na capacidade de interagir com os colaboradores para internalizar os objetivos da produção mais limpa e organizada. Apresentando também visão holística da real situação produtiva para descartes e geração de resíduos ao longo da produção, bem como as emissões de gases para manifestação no ar. Possuindo canais reversos e tratamentos específicos de água e gases poluentes. As indústrias estão todo tempo confrontando os seus interesses para habilitar sua produção na 
cidade, desta forma tornam-se crescente as medidas e soluções para melhora constantemente os canais reversos adotados.

Então se conclui que os gestores das indústrias de Brejo Santo enxergam a necessidade estratégica de trabalhar a logística reversa integrada com a sua cadeia de suprimento, de forma que essa integração possa baratear as práticas reversas em favor da existência dos bens de produção e participação com meio ambiente. Assim torna-se viável fazer logística reversa se isso estiver alinhado com os seus fornecedores, clientes e canais de distribuição.

Ao considerar que a pesquisa foi restrita ao estudo multi casos, havendo inclusão dos gestores apenas das indústrias de Brejo Santo-CE, se tratando de um público enxuto a investigação torna-se válida, porém não generalista. Observando-se como lacuna para estudos posteriores a viabilidade de implementação de programas que favoreçam a sustentabilidade tanto no âmbito da logística reversa, como de programas sociais e ambientais, caracterizando-se como uma pesquisa ação a partir de um estudo longitudinal.

A discussão apresentada pode servir como base para próximas pesquisas como: Responsabilidade social do gestor no século XXI; Gestão ambiental e responsabilidade social como elemento favorecer para a gestão; Custos x melhorias em sustentabilidade; Pequenas cidades com participação a nível nacional em gestão sustentável; Logística estratégica pelos maiores entraves percebida; e Canais reversos melhores aplicados às empresas.

\section{REFERÊNCIAS}

ADLMAIER, D.; SELLITTO, M. A.. Embalagens retornáveis para transporte de bens manufaturados: um estudo de caso em logística reversa. Revista Production, São Paulo, v.17, n.2, p.395-406, 2007.

ALVES, J. A.; SANTOS, A. P.. Logística lean para redução dos efeitos da variação da demanda no abastecimento de linhas de produção. Revista Perspectivas Contemporâneas, Campo Mourão, v.8, n.1, 2013.

BALLOU, R. H.. Logística empresarial. São Paulo: Atlas, 1993

BRASIL. Ministério do Meio Ambiente. Sistema Nacional De Informações Sobre A Gestão Dos Resíduos Sólidos. 2018.

BERTONCELLO, S. L. T.; CHANG JÚNIOR, J.. A importância da Responsabilidade Social Corporativa como fator de diferenciação. Facom, n.17, 2007.

CAMARGO, B. V.; JUSTO, A. M.. Tutorial para uso do software de análise textual IRAMUTEQ. Universidade Federal de Santa Catarina, 2013.

CELERE, M. S.; OLIVEIRA, A. S.; TREVILATO, T. M. B.; MUÑOZ, S. I. S.. Metais presentes no chorume coletado no aterro sanitário de Ribeirão Preto, São Paulo, Brasil, e sua relevância para saúde pública. Cad. Saúde Pública, Rio de Janeiro, 2007.

CONCEIÇÃO, A. L.; COELHO, V. T.; TORRES, R. P.; SOUSA, S. P.; SOARES NETO, J. L.. A importância do sistema de gestão ambiental (SGA): estudo de caso na empresa Grande Rio Honda em Palmas, Tocantins. 2011.

DIAS, V. T.; GUARNIERI, P.; XAVIER, L. H.. Logística reversa de computadores: Estudo de Caso em uma Instituição Financeira. São Leopoldo: 2014.

DIAS, R.. Gestão ambiental: responsabilidade social e sustentabilidade. 3 ed. São Paulo: Atlas, 2017.

DOMENICO, D.; MAGRO, C. B. D.; KROMBAUER, N. B.; COSER, F.. Responsabilidade Socioambiental aliada aos Incentivos Fiscais em empresas do ramo de Ciência, Tecnologia e Inovação. In: CONGRESSO DE CONTABILIDADE. Anais. Porto Alegre, 2015.

FORMIGONI, A.; SANTOS, S. C.; MEDEIROS, B. T.. Logística reversa e sustentabilidade para a melhoria da cadeia: uma abordagem no panorama da reciclagem pet no Brasil.

Revista Metropolitana de Sustentabilidade, Guarulhos, v.4, n.3, 2014.

GOMES, E. L.. O Processo da Gestão Ambiental nas Empresas e a Importância da Logística Reversa. REAC, Santa Luzia, v.2, n.1, p.47-54, 2013.

LACERDA, L.. Logística reversa: uma visão sobre os conceitos básicos e as práticas operacionais. Rio de Janeiro: COPPEAD/UFRJ, 2002.

LEITE, P. R.. Logística reversa nova área da logística empresarial. Revista Tecnologística, São Paulo, 2002. 
MACHADO, P. A. L.. Princípios da política nacional de resíduos sólidos. Revista do Tribunal Regional Federal, v.24, n.7, 2012.

MERRIAM, S. B.. Qualitative research and case study applications in education. San Francisco: Jossey-Bass, 1998.

MIKHAILOVA, I.. Sustentabilidade: evolução dos conceitos teóricos e os problemas da mensuração prática. Revista Economia e Desenvolvimento, n.16, 2004.

NASCIMENTO, L. F.. Gestão Ambiental e Sustentabilidade. Florianópolis: 2012.

NEIMAN, Z.; RABINOVICl, A.; SOLA, F.. A questão ambiental, a sustentabilidade e inter, pluri ou transdisciplinaridade. In: CUNHA, B. P.; AUGUSTIN, S.. Sustentabilidade ambiental: estudos jurídicos e sociais recurso eletrônico: estudos jurídicos e sociais. Caxias do Sul: Educs, 2014.

PEÇANHA, R. S.. ISE: Índice de Sustentabilidade Empresarial: Abordagem crítica sobre processo de seleção da carteira. In: MARCOVITCH, J.. Certificação e sustentabilidade ambiental: Uma análise crítica. São Paulo: 2012.

PEREIRA, A. L.; PEREIRA, S. R.. A cadeia de logística reversa de resíduos de serviços de saúde dos hospitais públicos de Minas Gerais: análise a partir dos conceitos da nova Política Nacional de Resíduos Sólidos Urbanos. Revista Desenvolvimento e Meio Ambiente, n.24, p.185-199, 2011.

PÓVOAS, M. S.. O amor na sociedade de risco: a sustentabilidade e as relações de afeto. In: SOUZA, M. C. S. A.; ARMADA, C. A.. Sustentabilidade meio ambiente e sociedade: reflexões e perspectivas. UNIPAR, 2015.

RICARDO, E.; MORAIS, C. B.; ZANELLA L. F. T.. Logística reversa: um estudo sobre o descarte do lixo eletrônico em
Fraiburgo-SC. Revista Unoesc \& Ciência, v.7, n.1, p.85-92, 2016.

RICK, E. F.; IBDAIWI, T. K. R.; ALMEIDA, D. M.; CORRÊA, J. S.; LOPES, L. F. D.. A Responsabilidade Socioambiental e a Gestão de Resíduos do Aço: um estudo de caso em uma empresa em Santa Maria - RS. Revista Eletrônica em Gestão, Educação e Tecnologia Ambiental, Santa Maria, v.19, n.2, p.595-608, 2015.

SANTOS, A. B.. O Processo Logístico como Estratégia Empresarial: um estudo de caso em uma indústria alimentícia de animais. Revista Formadores, v.10, n.1, 2017.

SEGRETI, J. B.; FARBER, J. C.; MONDINI, L. C.; A importância da gestão estratégica de custos logísticos. Porto Seguro: 2004.

SILVEIRA, D. T.; CÓRDOVA, F. P.. A Pesquisa Científica. In: GERHARDT, T. E.; SILVEIRA, D. T.. Métodos de pesquisa. Porto Alegre: UFRGS, 2009.

SOARES, J. A. S.; PEREIRA, S. S.; CÂNDIDO, G. A.. Gestão de resíduos sólidos e percepção ambiental: um estudo com colaboradores do campus i da universidade estadual da Paraíba. Revista Saúde e Meio Ambiente, Três Lagoas, v.4, n.1, p.39-54, 2017.

SUCENA, M.. Sistemas de armazenagem e manuseio. Estácio, 2012.

VIEIRA, A. A.; OLIVEIRA, E. S.; VIEIRA JÚNIOR, E. M.. A evolução da logística até o supply chain management. Goiânia: 2012.

YIN, R. K.. Estudo de caso: planejamento e métodos. 2 ed. Porto Alegre: Bookman, 2001.

A CBPC - Companhia Brasileira de Produção Científica (CNPJ: 11.221.422/0001-03) detém os direitos materiais desta publicação. Os direitos referem-se à publicação do trabalho em qualquer parte do mundo, incluindo os direitos às renovações, expansões e disseminações da contribuição, bem como outros direitos subsidiários. Todos os trabalhos publicados eletronicamente poderão posteriormente ser publicados em coletâneas impressas sob coordenação da Sustenere Publishing, da Companhia Brasileira de Produção Científica e seus parceiros autorizados. Os (as) autores (as) preservam os direitos autorais, mas não têm permissão para a publicação da contribuição em outro meio, impresso ou digital, em português ou em tradução. 